\title{
Benzene Oxidation on Boron-Doped Diamond Electrode: Electrochemical-Impedance Study of Adsorption Effects
}

\author{
Yuri Pleskov, Marina Krotova, Valerii Elkin, Valentin Varnin, and Irina Teremetskaya \\ Frumkin Institute of Physical Chemistry and Electrochemistry, Russian Academy of Sciences, Leninskii pr. 31, 119991 Moscow, Russia
}

Correspondence should be addressed to Yuri Pleskov, pleskov@electrochem.msk.ru

Received 29 March 2011; Revised 24 May 2011; Accepted 25 May 2011

Academic Editor: Carlos Alberto Martinez-Huitle

Copyright () 2012 Yuri Pleskov et al. This is an open access article distributed under the Creative Commons Attribution License, which permits unrestricted use, distribution, and reproduction in any medium, provided the original work is properly cited.

Benzene oxidation at a boron-doped diamond anode in $0.5 \mathrm{M} \mathrm{K}_{2} \mathrm{SO}_{4}$ aqueous solution is studied by cyclic voltammetry and electrochemical impedance spectroscopy. It is shown by measurements of differential capacitance and anodic current that in the ideal-polarizability potential region benzene either is not adsorbed at the diamond electrode or the benzene adsorption does not affect its capacitance. At more positive potentials, the adsorption of some intermediate of the benzene oxidation occurs at the electrode. The intermediate partially blocks the electrode surface and lowers the anodic current. The very fact of the electrode surface blocking is reflected in the complex-plane presentation of the impedance-potential plots.

\section{Introduction}

Boron-doped diamond (BDD) proved being a corrosionstable electrode material, particularly suitable for deep anodic oxidation [1]. Indeed, the diamond electrode makes it possible reaching high anodic potentials at which hydroxyl radicals $\left(\mathrm{OH}^{\bullet}\right)$ are formed at the anode surface (the oxygen evolution overpotential for diamond is sufficiently large, so this electrochemical reaction occurs with high current efficiency). The radicals oxidize organic and inorganic solutes (carboxylic acids, alcohols, phenols, aromatics) in the course of homogeneous chemical reaction. For this process, a kinetic model was suggested [2], according to which one of the two oxidation mechanisms is realized. In the potential region, where water is electrochemically stable, direct electron transfer occurs, whereas at high anodic potentials, indirect oxidation involving the above-mentioned hydroxyl radicals as mediator takes place (with concurrent oxygen evolution). The anodic oxidation at boron-doped diamond is an effective method of the nature and waste water purification from organic and inorganic pollutants $[3,4]$.

Benzene and its derivatives are typical water pollutants. The benzene oxidation at boron-doped diamond in $0.5 \mathrm{M}$ $\mathrm{H}_{2} \mathrm{SO}_{4}$ solution was studied in [5]. It was shown by using high-performance liquid chromatography that a mixture of the benzene oxidation intermediates (hydroquinone, resorcinol, $p$-benzoquinone, catechol, and phenol) was formed in solution at the anode potential of $2.5 \mathrm{~V}$ (versus $\mathrm{Ag} / \mathrm{AgCl}-$ electrode). The benzene complete incineration yielding $\mathrm{CO}_{2}$ occurs at potentials more positive than $2.5 \mathrm{~V}$. In our preceding paper [6], the benzene oxidation at boron-doped diamond anode was studied in $1 \mathrm{M} \mathrm{HCl}$ solution by electrochemical impedance spectroscopy, with special emphasis on the revealing of the role of adsorption in the process.

In this work, the benzene oxidation at boron-doped diamond anode was studied by electrochemical impedance spectroscopy with the purpose of having deeper insight in the oxidation process, in particular, in some delicate effects caused by the adsorption of benzene-oxidation intermediates at the electrode.

\section{Experimental}

2.1. Growth of Boron-Doped Diamond Films. Boron-doped diamond films were grown using hot-filament technique, by the depositing of diamond onto conducting silicon wafers from activated reaction gas phase. The gas phase activation was accomplished using a row of tungsten filaments arranged horizontally over the substrate surface at a distance of 5$10 \mathrm{~mm}$. The filaments were heated up to $\sim 2000^{\circ} \mathrm{C}$. The 
activator temperature was measured by monochromatic optical pyrometer through quartz window in the upper part of the reactor cap. The purpose of the activation is the formation, in the reaction gas, of large concentration of atomic hydrogen that ensures the selectivity of carbon deposition in the form of diamond.

A mixture of pure methane (ca. $1.2 \mathrm{vol} \%$ ) with hydrogen (ultra-high purity grade, mark A, the Nauka Company production) was subjected to the activation. The gas mixture composition was controlled by automated gas flow regulators; the full pressure in the reaction gas mixture was 30 36 Torr.

The substrates were KDB-10 silicon plates sized 12 by 12 by $1 \mathrm{~mm}$; the silicon resistivity was $10 \mathrm{Ohm} \mathrm{cm}$. The substrates were arranged on water-cooled substrate holder, in particular, a copper table provided with heater that maintained a preset temperature $850-890^{\circ} \mathrm{C}$. The substrate temperature was measured at the substrates' rear side by another optical pyrometer through a special channel in the sample holder.

To impart sufficiently large conductivity to the diamond films, they were doped, during their deposition, with boron. To this purpose, the reaction gas mixture was added by acetone-methanol-trimethylborate solution vapors. The B/C concentration ratio in the reaction mixture was estimated as 2500-3500 ppm.

To shorten the crystallization incubation time and set up high diamond crystallization-center density, the substrate surface was polished by superdispersed diamond polishing paste. The film average thickness was determined by sample weighing prior to and after the film growth; it came to $\sim 18 \mu \mathrm{m}$.

The as-grown films were subjected to heating in air at $520-530^{\circ} \mathrm{C}$ for $20 \mathrm{~min}$, to free the diamond surface from traces of nondiamond carbon. The nondiamond carbon has been deposited from the reaction gas phase after its activation has been ceased, that is, at the poorly controlled final deposition stage, during the samples cooling in the reactor.

2.2. Electrochemical Measurements. Electrochemical cellcomprised diamond working electrode and platinum auxiliary electrode; the interelectrode distance was $5-7 \mathrm{~mm}$. The anodic and cathodic compartments were not separated. The substrate with diamond film was pressed up to polished flange of round opening in the glass cell wall; a Teflon ring served as gasket. The working electrode active surface area was $\sim 0.3 \mathrm{~cm}^{2}$. All values of current, differential capacitance, and impedance components are given per $1 \mathrm{~cm}^{2}$ of geometrical surface.

The impedance spectra were taken using a SOLARTRON SI 1280B spectra analyzer (Great Britain) in two modes: " $f$-sweep" (over $1 \mathrm{~Hz}$ to $20 \mathrm{kHz}$ frequency range) and " $E$ sweep". At special cases, the impedance was measured using an R-5021 ac bridge (Kiev, Ukraine) over $20 \mathrm{~Hz}$ to $200 \mathrm{kHz}$ frequency range.

Potentiodynamic curves were taken using the SOLARTRON SI 1280B instrument. We used $0.5 \mathrm{M} \mathrm{K}_{2} \mathrm{SO}_{4}$ solution as indifferent electrolyte.

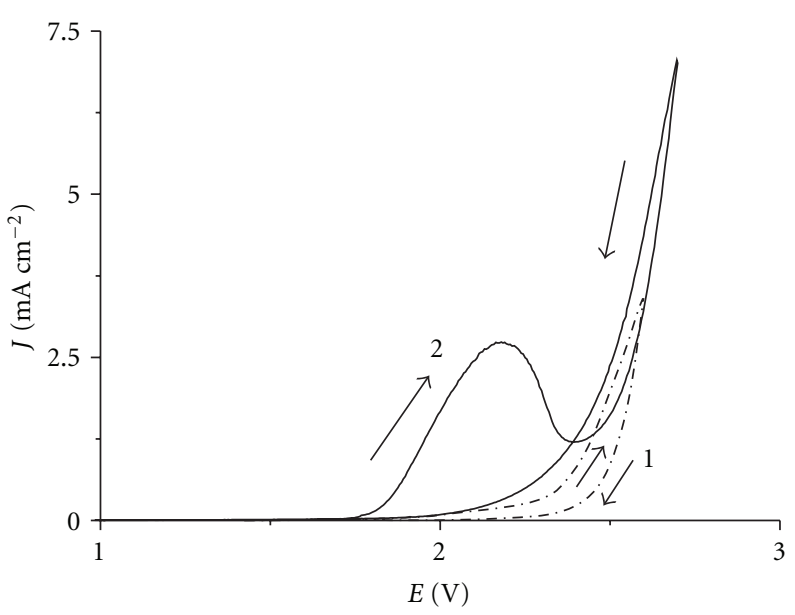

FIgure 1: Cyclic voltammograms in $0.5 \mathrm{M} \mathrm{K}_{2} \mathrm{SO}_{4}$ solution: (1) benzene-free solution, (2) benzene-saturated solution. (In what follows, all experimental results are given for the $0.5 \mathrm{M} \mathrm{K}_{2} \mathrm{SO}_{4}$ solution, unless otherwise stated.) Potential scan rate $20 \mathrm{mV} / \mathrm{s}$. Arrows show the direction of potential sweep.

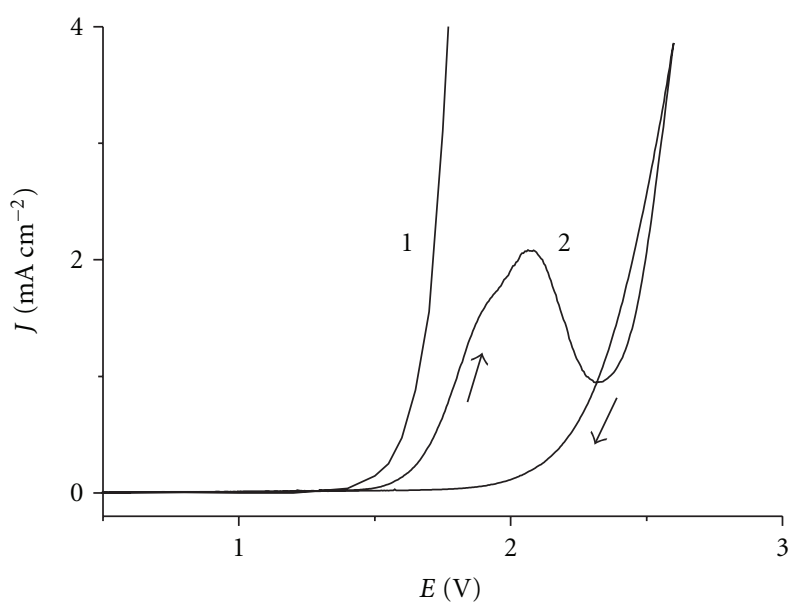

FIGURe 2: Cyclic voltammograms in $1 \mathrm{M} \mathrm{KCl}$ solution: (1) benzenefree solution, (2) benzene-saturated solution. Potential scan rate $20 \mathrm{mV} / \mathrm{s}$.

The working solution was $0.5 \mathrm{M} \mathrm{K}_{2} \mathrm{SO}_{4}$ saturated with benzene (reagent grade, mass fraction $99.8 \%$ ). The benzene solubility in water is $0.07 \%\left(\sim 2 \cdot 10^{-2} \mathrm{M}\right)$ at $22^{\circ} \mathrm{C}$ [7].

\section{Results and Discussion}

3.1. Potentiodynamic Curves. In Figure 1, we give cyclic voltammograms taken in benzene-free $0.5 \mathrm{M} \mathrm{K}_{2} \mathrm{SO}_{4}$ solution (curves 1 ) and in the benzene-containing solution (curves 2). The curves 1 measured in the pure indifferent electrolyte solution relate to the oxygen anodic evolution. The high overvoltage of the process should be emphasized; it is typical for diamond electrodes. On the curve 2 (direct run) taken in the presence of benzene, we see current maximum, followed by a minimum, then the second current rise occurred, which is due to the concurrent benzene oxidation and oxygen 


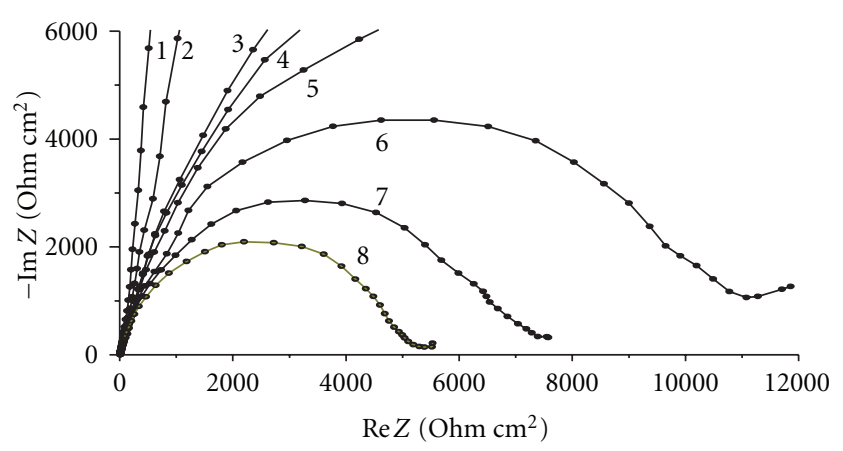

(a)

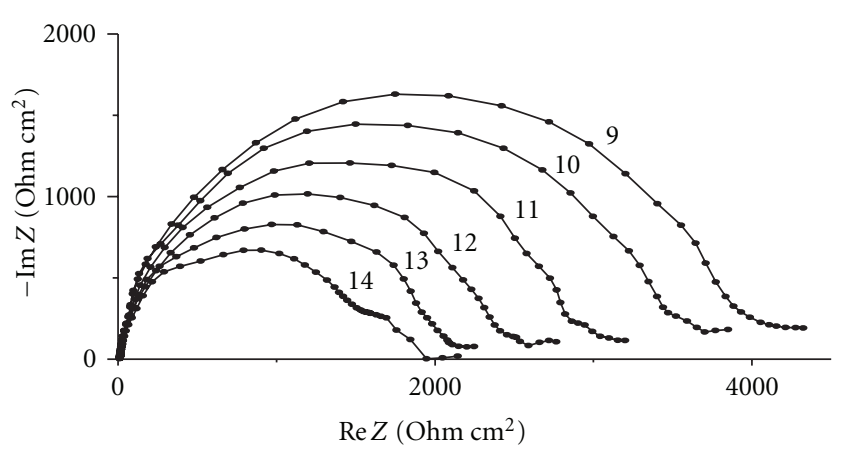

(b)

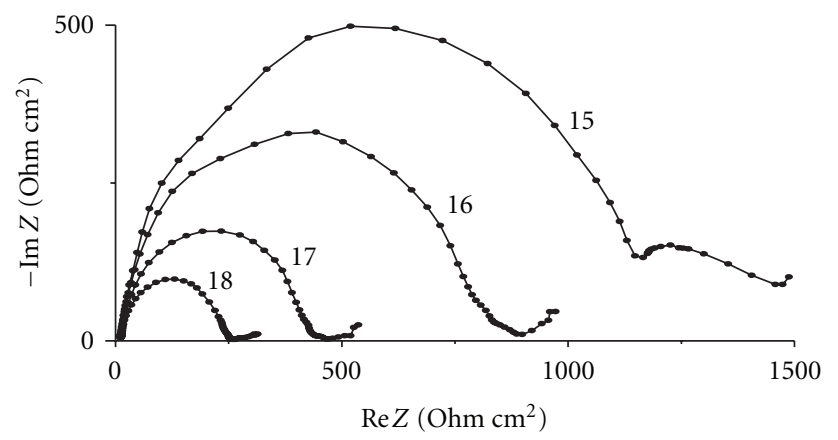

(c)

Figure 3: (a)-(c) Complex-plane plots of impedance spectra ( $f$-sweep) in $0.5 \mathrm{M} \mathrm{K}_{2} \mathrm{SO}_{4}$ benzene-free solution at potentials $E$ : (1) $0.80 \mathrm{~V}$; (2) $1.40 \mathrm{~V}$; (3) $1.60 \mathrm{~V}$; (4) $1.65 \mathrm{~V}$; (5) $1.70 \mathrm{~V}$; (6) $1.75 \mathrm{~V}$; (7) $1.80 \mathrm{~V}$; (8) $1.85 \mathrm{~V}$; (9) $1.95 \mathrm{~V}$; (10) $2.00 \mathrm{~V}$; (11) $2.05 \mathrm{~V}$; (12) $2.10 \mathrm{~V}$; (13) $2.15 \mathrm{~V}$; (14) $2.20 \mathrm{~V}$; (15) $2.25 \mathrm{~V}$; (16) $2.30 \mathrm{~V}$; (17) $2.35 \mathrm{~V}$; (18) $2.40 \mathrm{~V}$.

evolution. On basis of data on the differential capacitance (see below), we suggested that the decrease in the anodic current is mainly due to the blocking of anode surface by the benzene-oxidation intermediates that adsorb at the diamond electrode. This is confirmed, even if indirectly, by the fact that anodic curves taken repeatedly right after curve 2 lie much lower than this curve. This is analogous to the phenomenon described earlier for both benzene [6] and phenol [8] oxidation at BDD (see also Figure 2). As time goes by in currentless mode, the activity of electrode gradually restores. The electrode entire regeneration occurs in pure water after $12 \mathrm{~h}$-exposure. We note that the loss of BDD-electrode activity during the benzene oxidation was not mentioned in [5].

For comparison, we give in Figure 2 similar potentiodynamic curves taken in another indifferent electrolyte, namely, $1 \mathrm{M} \mathrm{KCl}$ solution. As such, the benzene oxidation curves measured in $\mathrm{K}_{2} \mathrm{SO}_{4}$ and $\mathrm{KCl}$ are qualitatively similar. The difference is in the background curves: $\mathrm{Cl}^{-}$ion is discharged (with chlorine gas evolution) at much less positive potential than that of benzene oxidation; hence, the electrode surface blocking by the benzene-oxidation intermediates affects this process too. Indeed, the $\mathrm{Cl}_{2}$ evolution onset potential is shifted toward more positive potentials. By contrast, the oxygen evolution during water oxidation, which occurs at more positive potentials than the $\mathrm{Cl}_{2}$ evolution, is not affected by the benzene oxidation.
3.2. The Impedance Spectra. The complex-plane plots of impedance spectra (that is, the $-\operatorname{Im} Z$ versus $\operatorname{Re} Z$ dependences) were measured at constant potential $E$ over the frequency $f$ range from $0.1 \mathrm{~Hz}$ to $15 \mathrm{kHz}$ (in what follows, we refer to them as $f$-sweep plots). The $f$-sweep plots were taken in benzene-free $0.5 \mathrm{M} \mathrm{K}_{2} \mathrm{SO}_{4}$ solution (Figure 3 ) and in the benzene-containing solution (Figure 4). In Figure 4, the potential range covered the ideal polarizability region (from 0.4 to $1.2 \mathrm{~V}$ ) and the anodic current rise (from 1.2 to $1.9 \mathrm{~V}$ ), Figure $4(\mathrm{a})$, the region of the current decay $(1.9$ to $2.0 \mathrm{~V})$, Figure $4(\mathrm{~b})$, and the region of the second rise of the current (from 2.0 to $2.40 \mathrm{~V}$ ), Figure 4(c) (in Figure 3, we divided the entire potential region into the like segments.)

We now analyze the shape of the $f$-sweep complexplane plots in more detail. At less positive potentials (curves 1, 2 in Figures 3 and 4), we have straight lines somewhat declined to vertical line, which is characteristic of equivalent circuits including a constant phase element (CPE). With the increasing of positive potential, the charge-transfer resistance decreased, and the plots became curved, eventually turning into somewhat depressed semicircles. The difference of the low-frequency and high-frequency cutoffs of the "semicircles" equals the charge-transfer "faradaic" resistance $R_{F}$. It should be emphasized that in the background electrolyte solution (Figure 3 ), the changing of $R_{F}$ is monotonic, whereas in the benzene-containing solution (Figure 4), the value of $R_{F}$ first decreased (see Figure 4(a), curves 1-8), then 


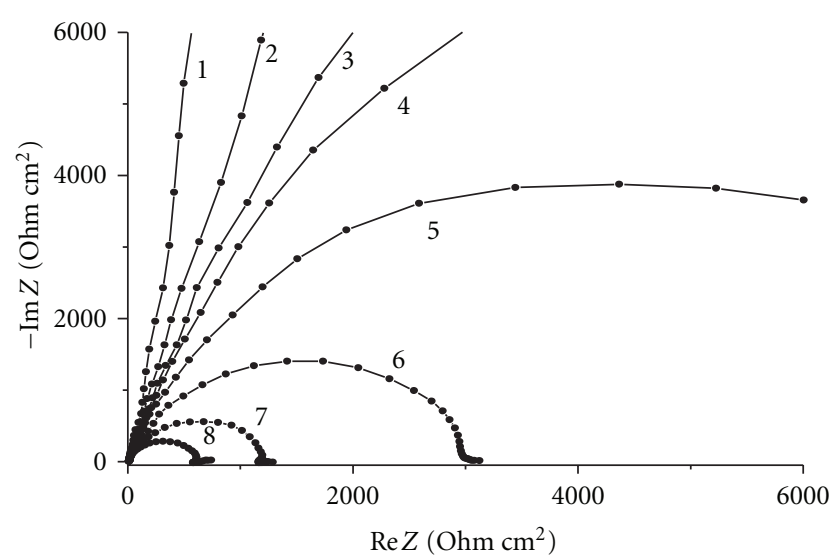

(a)

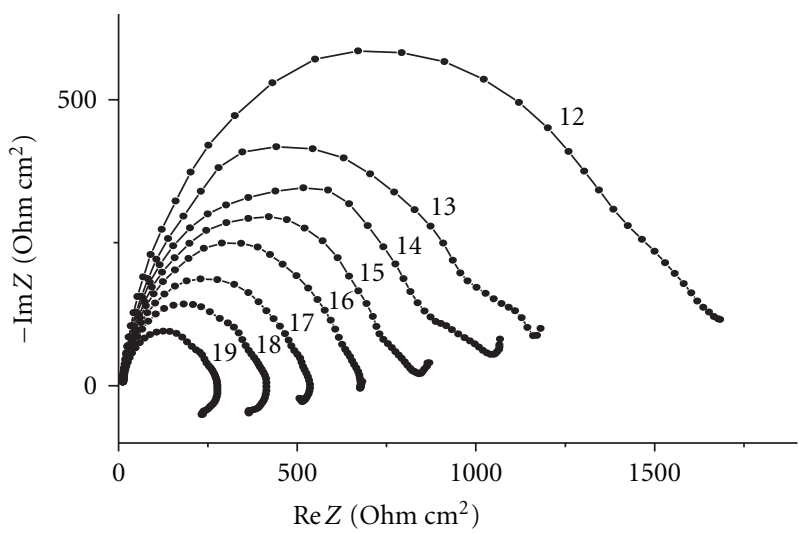

(c)

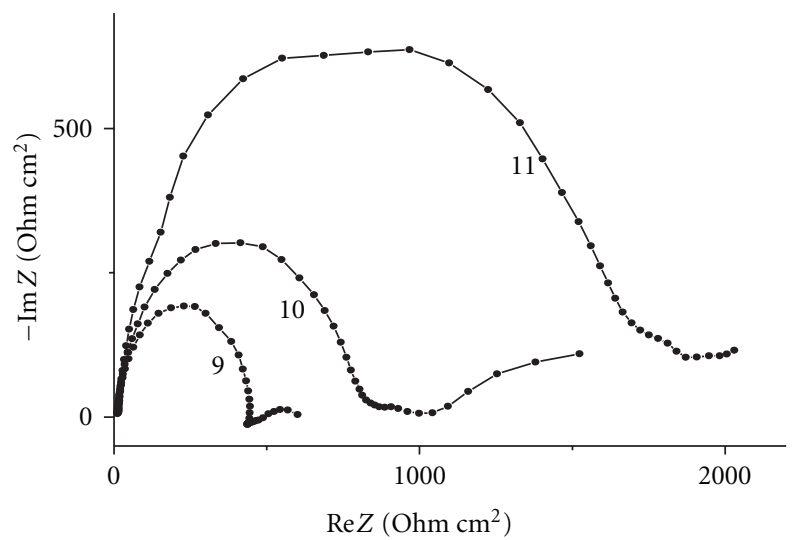

(b)

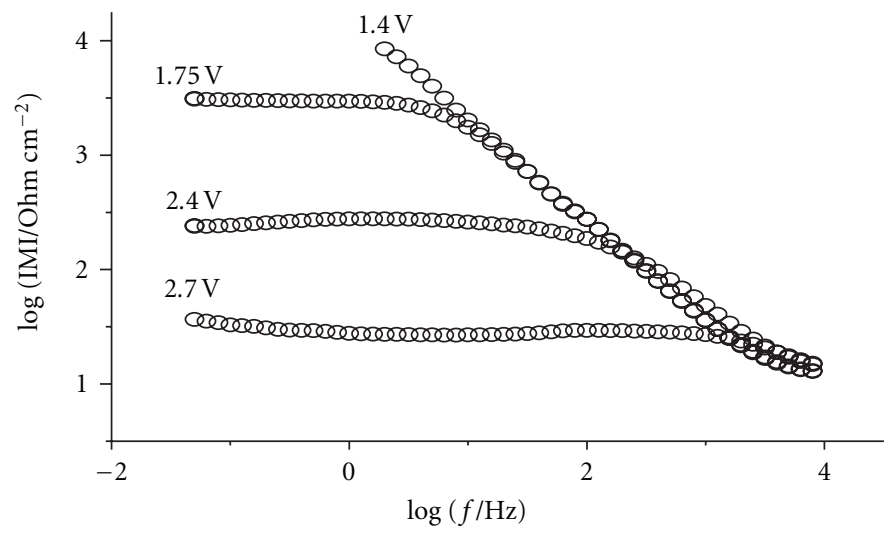

(d)

Figure 4: (a)-(c) Complex-plane plots of impedance spectra ( $f$-sweep) in $0.5 \mathrm{M} \mathrm{K}_{2} \mathrm{SO}_{4}$ benzene-saturated solution at potentials $E$ : (1) $0.80 \mathrm{~V}$; (2) $1.40 \mathrm{~V}$; (3) $1.60 \mathrm{~V}$; (4) $1.65 \mathrm{~V}$; (5) $1.70 \mathrm{~V}$; (6) $1.75 \mathrm{~V}$; (7) $1.80 \mathrm{~V}$; (8) $1.85 \mathrm{~V}$; (9) $1.90 \mathrm{~V}$; (10) $1.95 \mathrm{~V}$; (11) $2.00 \mathrm{~V}$; (12) $2.05 \mathrm{~V}$; (13) $2.10 \mathrm{~V}$; (14) $2.15 \mathrm{~V}$; (15) $2.20 \mathrm{~V}$; (16) $2.25 \mathrm{~V}$; (17) $2.30 \mathrm{~V}$; (18) $2.35 \mathrm{~V}$; (19) $2.40 \mathrm{~V}$. (d) The Bode plot (bi-logarithmic dependence of the impedance modulus on the frequency).

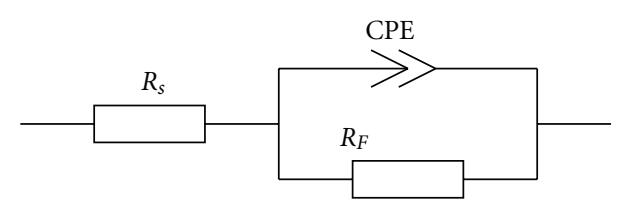

(a)

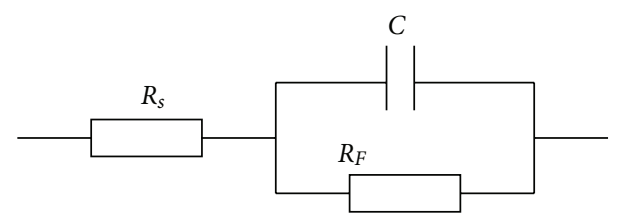

(b)

FIGURE 5: Equivalent circuits: (a) ZARC and (b) the Ershler-Randles circuit. CPE is the constant phase element, $C$ is the differential capacitance, $R_{\mathrm{F}}$ is the charge-transfer resistance, and $R_{\mathrm{s}}$ is the series resistance.

increased (Figure 4(b), curves 9-11), and finally decreased again (Figure 4(c), curves 12-19). It is easy to see that the character of changes in the value of $R_{F}$ closely correlates with the shape of the potentiodynamic curve 2 in Figure 1.

The high-frequency "halves" of the $f$-sweep complexplane plots of impedance spectra (from the high-frequency cutoff up to the maximum) resemble more or less perfect semicircles, whereas the low-frequency halves are distorted by some slow processes whose nature is unknown. (Some considerations thereon are given in our earlier work [6]).

The high-frequency "halves" of the impedance spectra plots were interpreted by using a modified Ershler-Randles equivalent circuit called ZARC [9] (Figure 5(a)), in which a constant phase element (CPE) is substituted for the differential capacitance $C$. The ZARC circuit is widely used in the electrochemical impedance spectroscopy practice. Here the CPE impedance is $Z_{\mathrm{CPE}}=\sigma^{-1}(i \omega)^{-a}$, where $\sigma$ is the frequency-independent factor; the exponent $a$ determines the character of frequency dependence; $\omega=2 \pi f$ is the ac angular frequency; $i=\sqrt{-1}$ is the imaginary unity.

The elements of the circuit, namely, the CPE parameters (the frequency-independent factor $\sigma$ and the exponent $a$ ), the charge-transfer resistance $R_{F}$ and series resistance $R_{s}$ were calculated from the impedance spectra (Figures 3 and 4 ) 


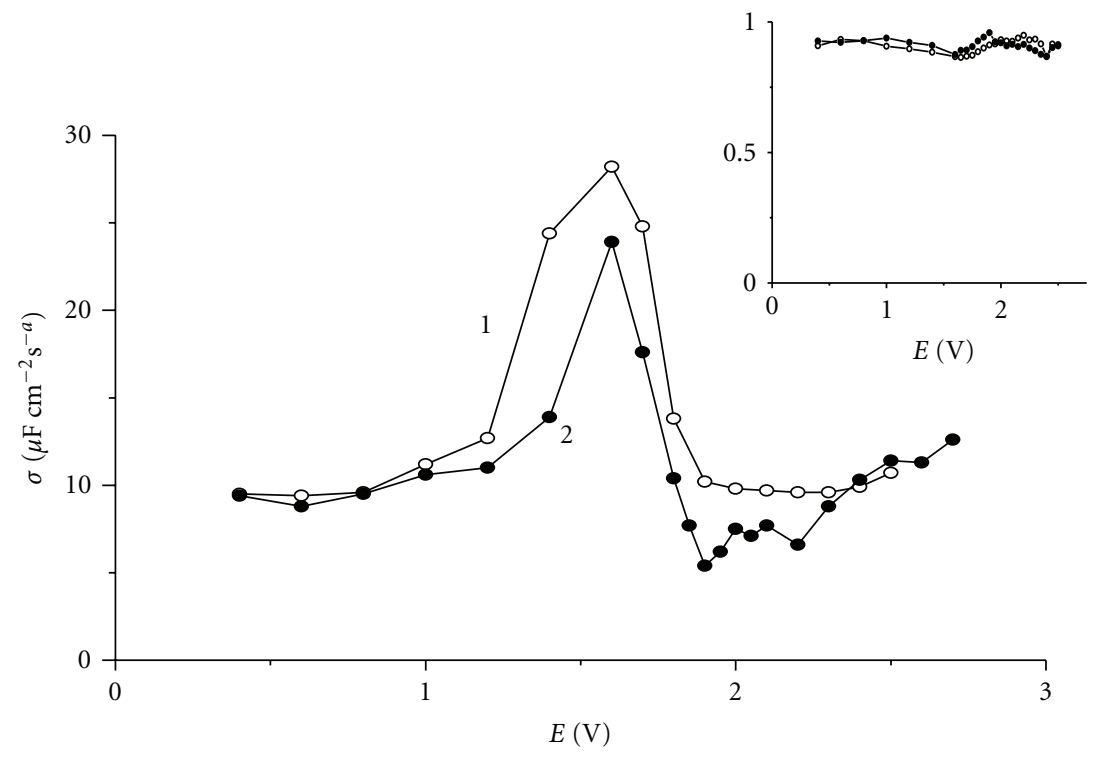

FIgURe 6: Potential dependence of $\sigma$ and $a$ (inset): (1) benzene-containing solution; (2) benzene-free solution.

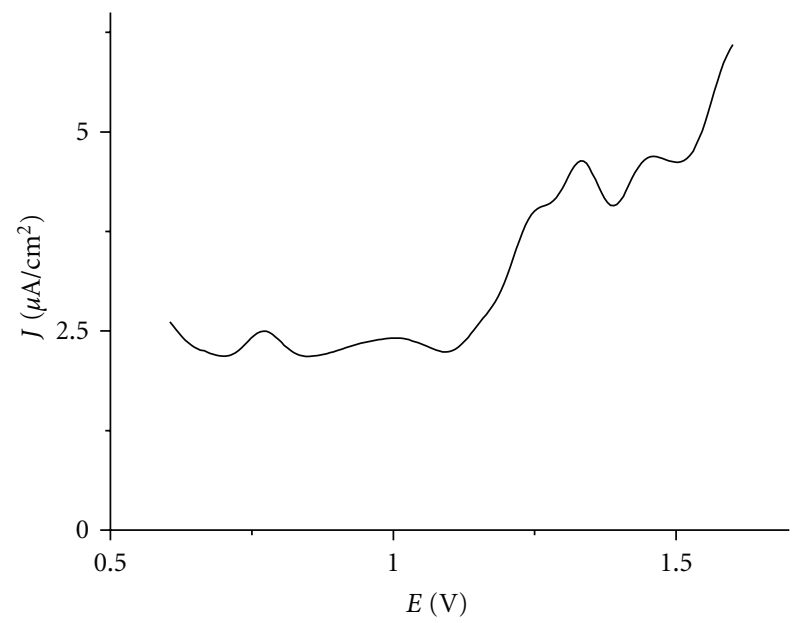

FIGURE 7: Residual current in indifferent electrolyte solution.

by a standard fitting procedure; the standard deviation of calculated values from those experimentally measured did not exceed $10^{-3}$. (The experimentally measured impedance spectra were originally processed by using two equivalent circuits: the Ershler-Randles circuit (containing the capacitance $C$, see Figure 5(b)) and the ZARC circuit (containing the CPE, Figure 5(a)). When using Figure 5(a) circuit, the fitting relative error appeared being much less; therefore, we accepted this very circuit in our impedance calculations. We note that the numerical values of the differential capacitance $C$ (in $\mu \mathrm{F} / \mathrm{cm}^{2}$ ) and the factor $\sigma$ (in its accepted units) are quantities of the same order of magnitude, e.g., at $E=0.7 \mathrm{~V}$, we have $C=5.7, \sigma=11$. In what follows, we shall often refer to both $C$ and $\sigma$ as "capacitance", without loss of generality).

The Bode plot (the frequency dependence of the impedance modulus $|M|$, Figure $4(\mathrm{~d})$ ) is consistent with

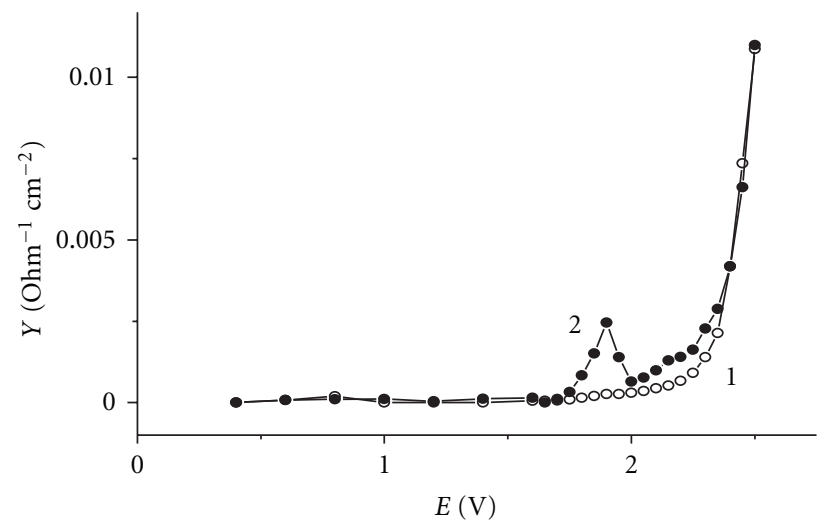

FIGURe 8: Potential dependence of differential conductivity: (1) benzene-free solution and (2) benzene-containing solution.

the results of the above analysis. At the potential of $1.4 \mathrm{~V}$ (in the ideal polarizability region), the straight line reflects but the CPE in the equivalent circuit. When the oxidation current flows, the charge-transfer resistance $R_{F}$ decreases (the more so, when the potential $E$ increased from 1.75 to $2.7 \mathrm{~V}$ ) and thus contributes less to the $|M|$ value, the $\log |M|$ versus $\log f$ dependence saturates in the lowfrequency region. In the high-frequency limit, we still have not reached saturation at $\sim 10000 \mathrm{~Hz}$ with our instrument; yet, we see faint resemblance of the saturation at a value of $\leq 10 \mathrm{Ohm} \mathrm{cm}^{2}$, which is close to the high-frequency cutoff in the complex-plane plots (Figures 3(a) and 4(a)). It is the solution resistance $R_{s}$ (see Figure 5) that contributes to $|M|$, along with the charge-transfer resistance $R_{F}$ and manifests itself at the higher frequencies.

In Figure 6, we show the potential dependence of $\sigma$ and $a$ (inset). In the ideal polarizability region (at potentials $E$ more negative than $1.2 \mathrm{~V}$ ), the differential capacitance (more 


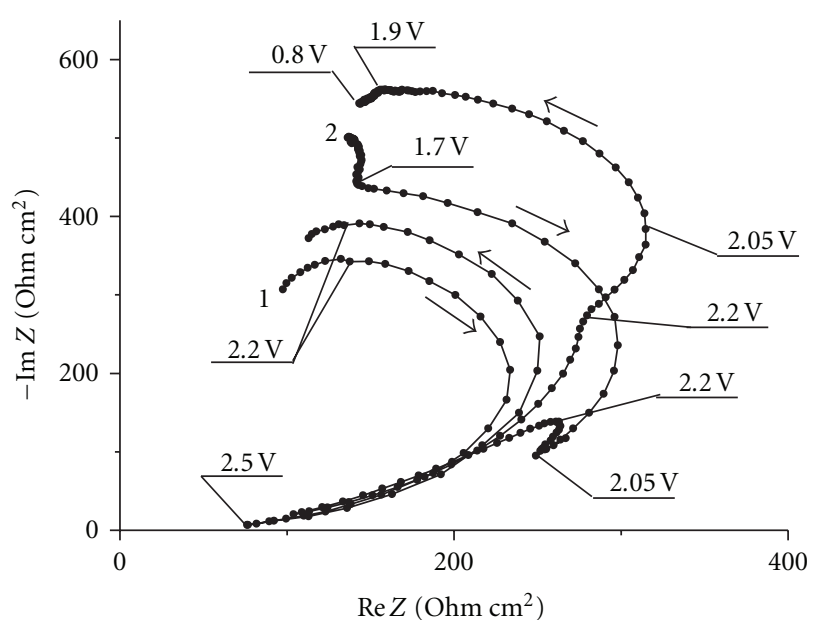

Figure 9: Complex-plane plots of impedance spectra (E-sweep): (1) benzene-free solution and (2) benzene-containing solution. Arrows show the direction of potential sweep; the relevant potential values are shown at the curves.

precisely, the factor $\sigma$ ) depends but little on $E$; it is nearly the same both in the absence and in presence of benzene (compare curves 1 and 2 in Figure 6). Therefore, we conclude that in this potential region benzene does not adsorb on the diamond electrode (or its adsorption does not affect the electrode capacitance).

At potentials $1.5-1.6 \mathrm{~V}$, the capacitance reaches its peak value. In the same potential region, the currentpotential dependence in the indifferent electrolyte solution also reaches its peak value (a few $\mu \mathrm{A} / \mathrm{cm}^{2}$ ), see Figure 7 . According to [10], this current maximum is caused by the anodic oxidation of nondiamond $\left(s p^{2}\right.$-) carbon composing intercrystalline boundaries; this material is less resistant toward oxidation than the crystalline $\left(s p^{3}\right.$-)diamond. It seems not unwise to relate the capacitance (or pseudocapacitance?) maximum to the $s p^{2}$-carbon oxidation current.

At still more positive potentials where benzene is subject to active oxidation, the capacitance in the presence of benzene is somewhat lower than in benzene-free solution. This can be explained by the adsorption of some intermediate of the benzene oxidation on the electrode, which results in the formation of dielectric interlayer [11]. In all probability, it is the same intermediate that blocks the anodic current (see Figures 1 and 2). At the potential of $2.2 \mathrm{~V}$, the adsorbed product desorbs from the electrode or is subjected to further anodic oxidation, and the capacitance increased again.

The exponent $a$ somewhat differs from 1 ; it equals 0.8 to 0.9 (inset to Figure 6). Its weakly pronounced potential dependence may evidence some distribution of the reactants' charge-transfer and mass-transfer activation parameters over the electrode surface [12]. Alternatively, it may be caused by concurrent adsorption of several benzene-oxidation intermediates with different activation energies.

The potential dependence of the differential faradaic conductivity of the electrode/electrolyte interface $Y=1 / R_{F}$ (Figure 8) resembles qualitatively the potential dependence of anodic current. In the region of the current blocking,

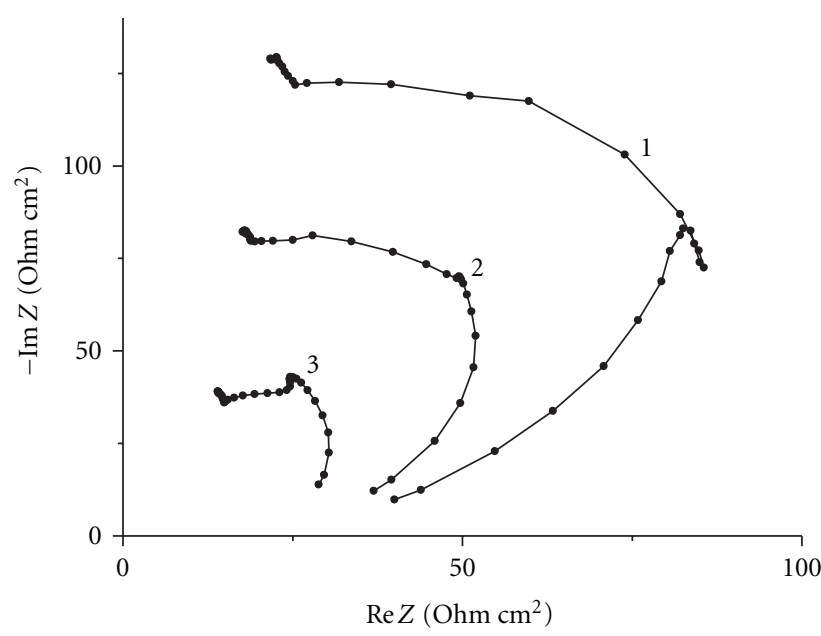

Figure 10: Complex-plane plots of impedance spectra (E-sweep, only direct runs), demonstrating the frequency effect on the small arc position: (1) $300 \mathrm{~Hz}$, (2) $500 \mathrm{~Hz}$, (3) $1000 \mathrm{~Hz}$.

the conductivity drops down, due to the adsorption of an intermediate. Then $Y$ increased again, thus reflecting the benzene oxidation and the parallel process of oxygen evolution (owing to water anodic oxidation).

3.3. The "E-Sweep Complex-Plane Plots" of Impedance Spectra. In addition to the complex-plane plots of impedance spectra obtained at constant potential and varying ac frequency (see the preceding Section), we measured complex-plane plots (the $-\operatorname{Im} Z$ versus $\operatorname{Re} Z$ dependences) of impedance at constant frequency, varying the potential $E$ (the so-called $E$-sweep, Figure 9). They were taken both in the indifferent electrolyte (curves 1) and in the presence of benzene (curves 2).

By inspecting the spectra in Figure 9, we see that, to the first approximation, they comprise two parts, namely, nearly vertical lines in the ideal polarizability region (which are even better pronounced at higher frequencies, see Figure 11(b) below), and "vertically arranged semicircles" that can be related to the charge transfer process at the interface during the oxidation process. It is these second parts that give information on the electrode reaction [13].

The equation describing these "polarization complexplane plots" of impedance spectra can be easily derived for the simplest model. When the charge-transfer impedance includes contributions from the differential capacitance $C$ and faradaic conductivity $Y_{F}$ (connected in parallel in equivalent circuit) to the charge transfer flux

$$
Z_{k}=\frac{1}{i \omega C+Y_{F}}
$$

the equation for the complex-plane plot of the impedance is

$$
\operatorname{Re}^{2} Z_{k}+\left(\operatorname{Im} Z_{k}+\frac{1}{2 \omega C}\right)^{2}=\left(\frac{1}{2 \omega C}\right)^{2} .
$$

With varying $Y_{F}$, we obtain a semicircle whose radius is inversely proportional to the electrical double layer capacitance $C$ and the angular frequency $\omega$. The distance of the 


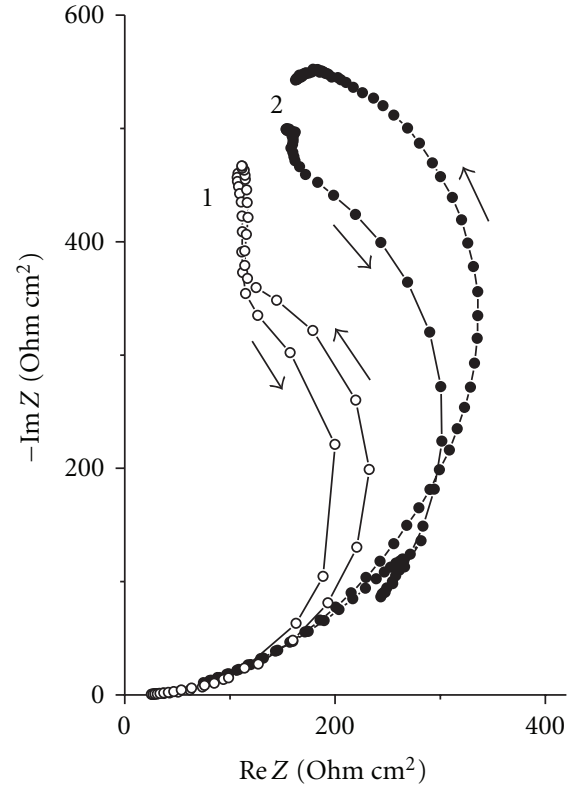

(a)

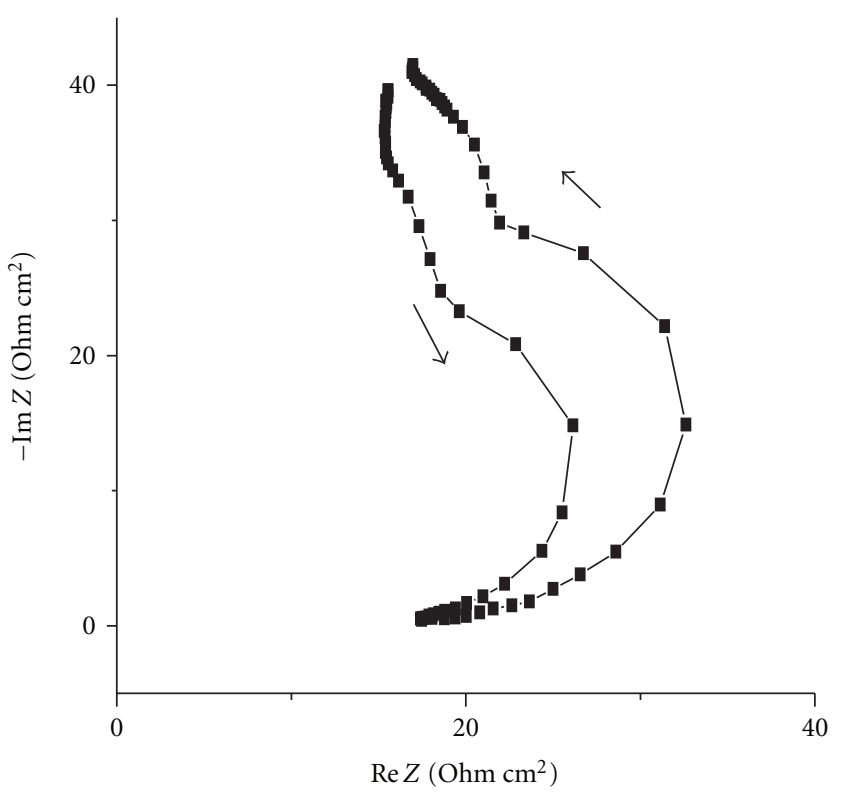

(b)

Figure 11: Complex-plane plots of impedance spectra (E-sweep) in $1 \mathrm{M} \mathrm{KCl}$ solution, demonstrating the frequency effect on the small arc position. (a) $60 \mathrm{~Hz}$ : (1) benzene-free solution and (2) benzene-containing solution. (b) $1000 \mathrm{~Hz}$, benzene-containing solution. Arrows show the direction of potential sweep $(0.4-2.5 \mathrm{~V})$.

semicircle center to the real component axis equals the semicircle radius.

We note that after strong anodic polarization and subsequent return of potential to its initial (cathodic) value (see arrows in Figure 9, curves 1) the curve depicts a semicircle of larger radius (compare the curves obtained in the direct and the reverse run). At a fixed frequency, this can only be caused by decrease in the differential capacitance. The plausible reason of the decrease in the capacitance, hence, occurrence of the hysteresis may be irreversible adsorption of oxygen (formed during the water decomposition) and (in the presence of benzene) coadsorption of the benzene-oxidation intermediates.

When benzene is present in the solution (Figure 9, curves 2 ), the $-\operatorname{Im} Z$ versus $\operatorname{Re} Z$ plots of direct run, measured at relatively low frequencies $(30-100 \mathrm{~Hz})$, show a short segment shaped as small arc. It is observed right in the potential region where the voltammogram (Figure 1, curve 2) showed a current peak and subsequent current decay. The small arc separates the semicircle's segments of different radii. At the reverse run of the curves the small arc used to be absent, probably, due to the electrode surface blocking by the oxidation intermediates. Importantly, at the reverse run of the cyclic voltammograms in the benzene-containing solution (Figure 1, curve 2), the benzene oxidation current is also absent right in the potential region when the direct voltammogram shows the current peak. Evidently, it is due to the surface blocking by the benzene-oxidation intermediate products. Thus, the small arc in the E-sweep impedance curves is a reflection of the anodic current maximum in the voltammogram. In the absence of faradaic current, the small

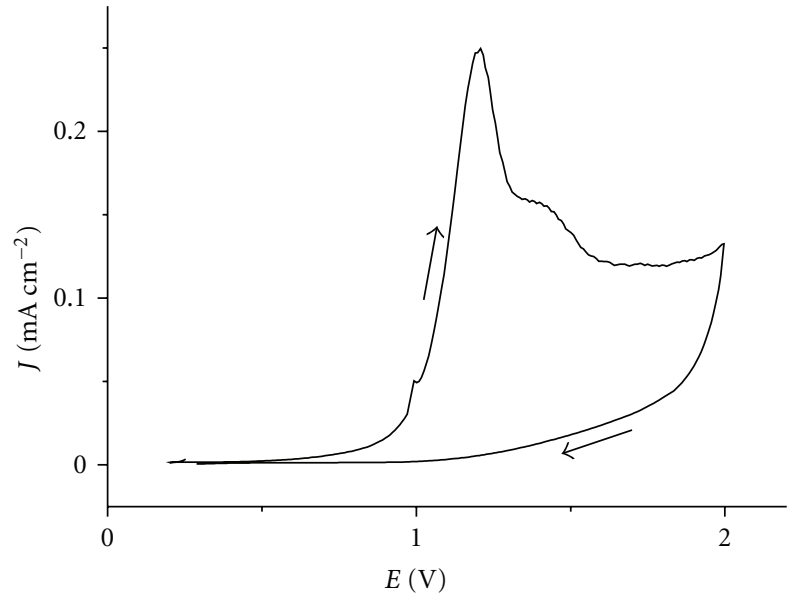

FIgURE 12: Cyclic voltammograms in phenol-containing solution. Potential scan rate $20 \mathrm{mV} / \mathrm{s}$. Arrows show the direction of potential sweep.

arc in the reverse run of impedance complex-plane plots is also absent.

From the methodical point of view, it is of interest to reveal the effect of the ac measuring frequency on the position of the small arc in the impedance curve relative to the "central" (characteristic) point with the maximal $\operatorname{Re} Z$. In the latter point, the capacitive and charge-transfer currents (hence, $|\operatorname{Im} Z|$ and $\operatorname{Re} Z$ ) are equal to each other. The position of the small arc relative to this characteristic point in the $-\operatorname{Im} Z$ versus $\operatorname{Re} Z$ plots is determined by the 


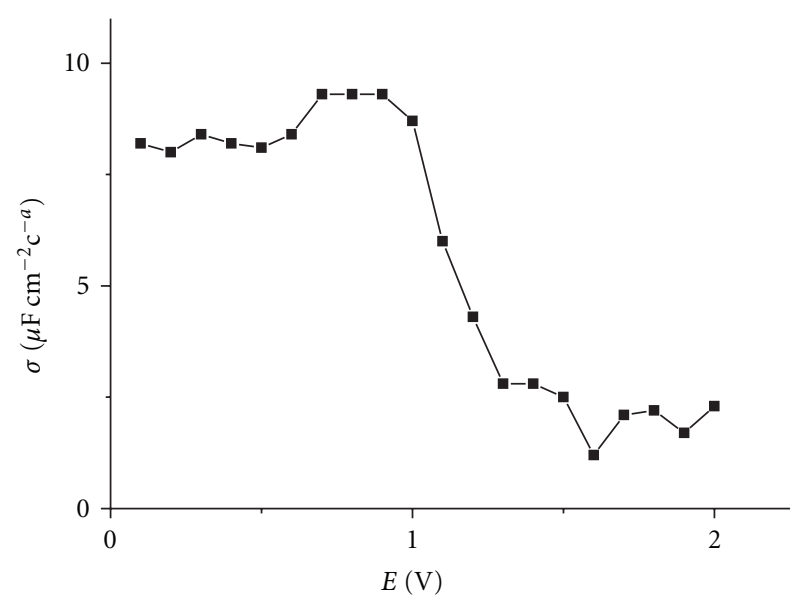

Figure 13: Potential dependence of $\sigma$ in phenol-containing solution. Compare the background curve 2 in Figure 6.

capacitive-to-charge transfer current ratio. In Figure 10, we compare the small arc position for three frequency values. At the lower frequency $(300 \mathrm{~Hz}$, curve 1$)$, the small arc is very well pronounced. With the increasing of the ac frequency (to $500 \mathrm{~Hz}$ ), the current passing through the circuit's capacitive element increases; therefore, in the "new" characteristic point of the $-\operatorname{Im} Z$ versus $\operatorname{Re} Z$ plot, at the constant capacitance, the ohmic (charge-transfer) resistance appears being relatively less. And the small arc (corresponding to certain potential region with its characteristic charge-transfer resistance) at the higher frequency appeared being shifted closer to cathodic potentials, see curve 2 . In this point, the capacitive-to-charge transfer current ratio is less than in the characteristic point. At still higher frequency $(1000 \mathrm{~Hz})$ the small arc almost reached the boundary of the ideal polarizability region (curve 3 ).

However, it appeared impossible to greatly increase the measuring frequency in the $\mathrm{K}_{2} \mathrm{SO}_{4}$ solution, in all probability due to its insufficiently large conductivity. We succeeded to do this in the better conducting $\mathrm{KCl}$ solution. In Figure 11, we clearly see that the small arc can be observed in $\mathrm{KCl}$ as well, however, at rather low frequencies $(60 \mathrm{~Hz}$, Figure 11(a)). By contrast, at higher frequencies $(1-10 \mathrm{kHz})$, it disappeared (Figure 11(b)), in agreement with the abovegiven explanation.

3.4. Measurements in Phenol Solution. Above we showed that in the potential region of benzene oxidation the BDDelectrode surface is blocked by some intermediate products of the oxidative process. Among them, the former one in the reaction path is phenol that appears through a two-electron oxidation reaction (see, e.g., [8]). To reveal its possible effect on the impedance and charge transfer in the benzene system under study, we measured the potential dependences of anodic current (Figure 12) and differential capacitance (more precisely, the factor $\sigma$, Figure 13 ) in $0.5 \mathrm{M} \mathrm{K}_{2} \mathrm{SO}_{4}$ solution in the absence and in the presence of phenol.

The cyclic voltammogram (Figure 12) by and large is similar to that given in [8]. The potential dependences of the capacitance in the ideal polarizability region both in the benzene- and phenol-containing solutions are basically similar (compare Figures 6 and 13). This allowed us to conclude that phenol, like benzene, does not adsorb on the diamond electrode. Hence, it is an intermediate other than phenol (that is, in higher oxidation state) that blocks the benzene oxidation current at the BDD electrode.

Interestingly, unlike Figure 6, no capacitance maximum is observed in the phenol solution at the potential of 1.5$1.6 \mathrm{~V}$ (Figure 13) where phenol is oxidized (whereas benzene is still stable against oxidation). Obviously, the phenoloxidation intermediate adsorbs at the BDD and affect its surface properties in this potential region, in particular, lowering the capacitance.

\section{Conclusions}

Benzene oxidation at boron-doped diamond electrodes in $0.5 \mathrm{M} \mathrm{K}_{2} \mathrm{SO}_{4}$ aqueous solution is studied by cyclic voltammetry and electrochemical impedance spectroscopy. It is shown that in the ideal polarizability potential region benzene either does not adsorb at the diamond electrode or its adsorption does not affect the electrode capacitance. At more positive potentials, the " $E$-sweep" impedance measurements showed that the adsorption of some intermediate of benzene oxidation occurs at the electrode. The intermediate partially blocks the electrode surface and lowers the anodic current of benzene oxidation, however, without any effect on the oxygen evolution process. It is concluded that the electrode surface blocking is caused by an intermediate other than phenol.

\section{Acknowledgment}

This work was supported by the Russian Foundation for Basic Research, project no. 10-03-00011.

\section{References}

[1] Yu.V. Pleskov, Elektrokhimiya Almaza (Electrochemistry of Diamond), URSS, Moscow, Russia, 2003.

[2] Ch. Comninellis, I. Duo, P.-A. Michaud, D. Marselli, and S.-M. Park, "Application of synthetic boron-doped diamond electrodes in electrooxidation processes," in Diamond Electrochemistry, A. Fujishima, Ya. Einaga, T. N. Rao, and D. A. Tryk, Eds., Elsevier, Amsterdam, The Netherlands, 2005.

[3] M. Fryda, T. Matthée, S. Mulcahy, A. Hampel, L. Schäfer, and I. Tröster, "Fabrication and application of Diachem electrodes," Diamond and Related Materials, vol. 12, no. 10-11, pp. 19501956, 2003.

[4] W. Haenni, Ph. Rychen, M. Fryda, and C. Comninellis, "Industrial applications of diamond electrodes," in Semiconductors and Semimetals, C. E. Nebel and J. Ristein, Eds., vol. 77 of Thin-film Diamond II, p. 149, 2004.

[5] R. T. S. Oliveira, G. R. Salazar-Banda, M. C. Santos et al., "Electrochemical oxidation of benzene on boron-doped diamond electrodes," Chemosphere, vol. 66, no. 11, pp. 21522158, 2007.

[6] Yu.V. Pleskov, M. D. Krotova, V. V. Elkin, V. P. Varnin, and I. G. Teremetskaya, "Benzene oxidation on BDD anode: the electrochemical impedance study," Elektrokhimiya. In press. 
[7] B. P. Nikol'skii et al., Ed., Chemist's Handbook, vol. 2, Gos. Khim. Izd., Leningrad, Russia, 1951.

[8] J. Iniesta, P. A. Michaud, M. Panizza, G. Cerisola, A. Aldaz, and C. Comninellis, "Electrochemical oxidation of phenol at boron-doped diamond electrode," Electrochimica Acta, vol. 46, no. 23, pp. 3573-3578, 2001.

[9] J. R. Macdonald, Ed., Impedance Spectroscopy, John Wiley \& Sons, New York, NY, USA, 1988.

[10] H. B. Martin, A. Argoitia, U. Landau, A. B. Anderson, and J. C. Angus, "Hydrogen and oxygen evolution on boron-doped diamond electrodes," Journal of the Electrochemical Society, vol. 143, no. 6, pp. L133-L136, 1996.

[11] V. I. Melik-Gaikazyan, "The determination of kinetics of organics adsorption from impedance measurements," Zhurnal Fizicheskoi Khimii, vol. 26, p. 560, 1952.

[12] Z. B. Stoynov, B. M. Grafov, B. S. Savova-Stoynova, and V. V. Elkin, Elektrokhimicheskii Impedans (Electrochemical Impedance), Nauka, Moscow, Russia, 1991.

[13] V. V. Elkin, V. Y. Mishuk, M. A. Abaturov, and B. M. Grafov, "Polarization hodograph of the second-order impedance for the charge transfer proceeding under kinetic control," Russian Journal of Electrochemistry, vol. 34, no. 2, pp. 126-132, 1998. 


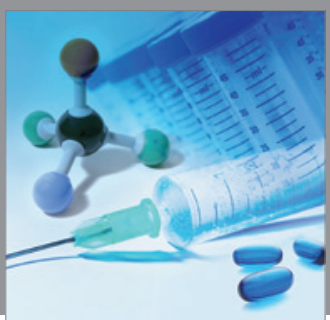

International Journal of

Medicinal Chemistry

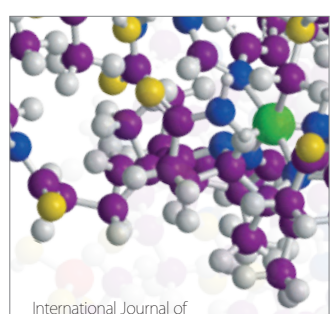

Carbohydrate Chemistry

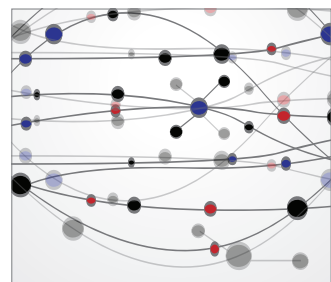

The Scientific World Journal
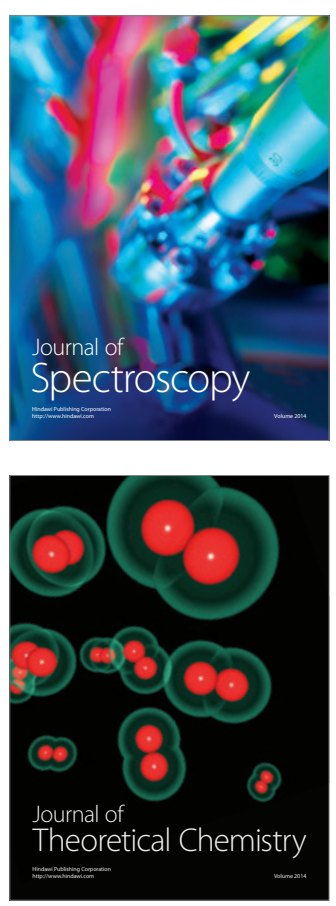
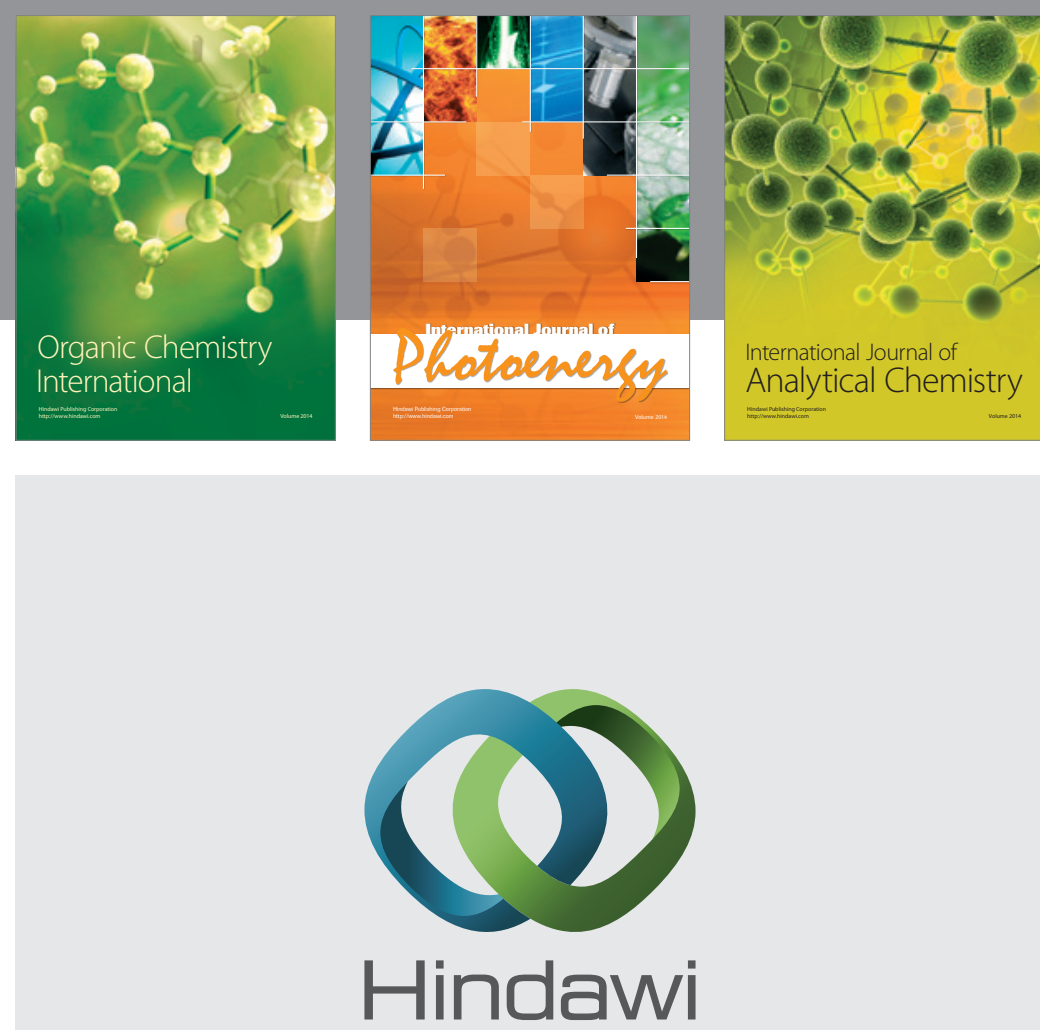

Submit your manuscripts at

http://www.hindawi.com
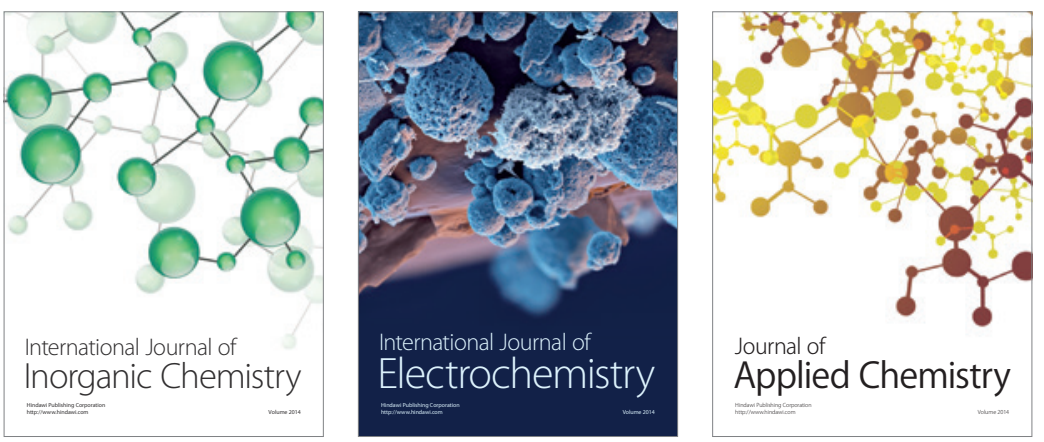

Journal of

Applied Chemistry
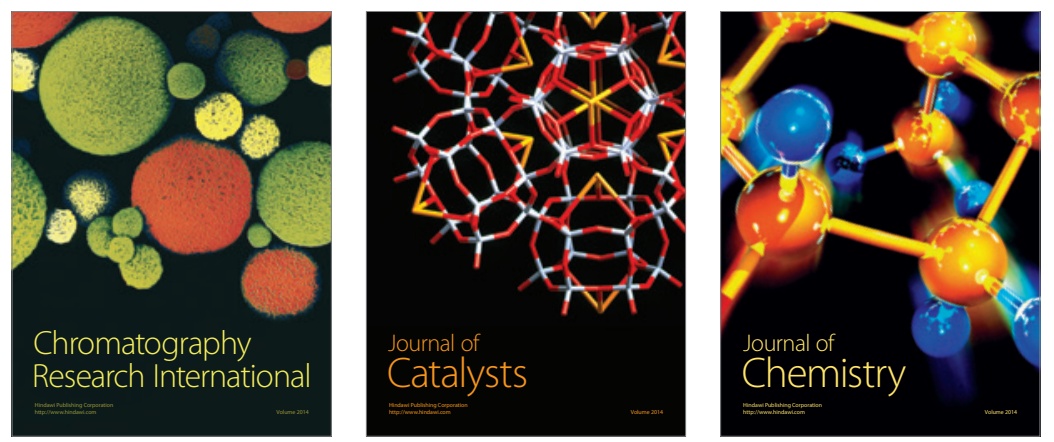
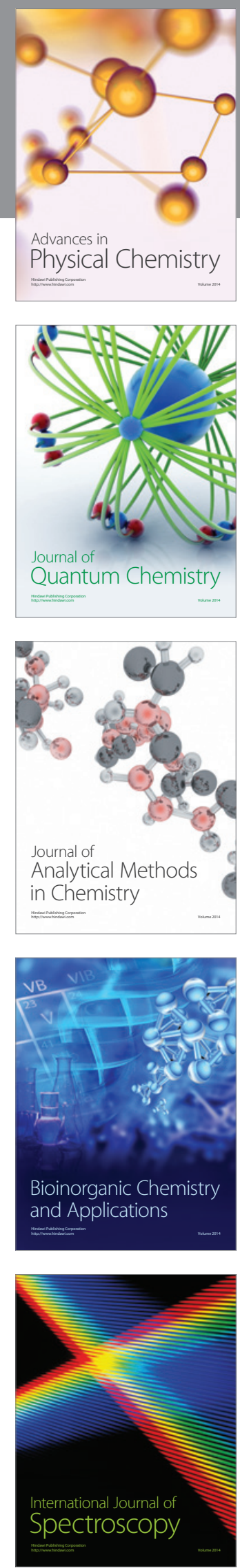